\title{
COMPARISON BETWEEN MICROSCOPIC AND ENDOSCOPIC ASSISTED TYMPANOPLASTY- A BEGINNER-OTOLOGIST'S PERSPECTIVE
}

\author{
Murari M1 ${ }^{1}$ Mallick Ajay²
}

${ }^{1}$ Speciality Registrar, ENT \& HNS, Tameside General Hospital, Ashton Under Lyne, Manchester, UK. 2Professor, Department of ENT Base Hospital \& Army College of Medical Sciences, New Delhi, India.

ABSTRACT
BACKGROUND
Middle ear surgery including Tympanoplasty, has traditionally been performed using a surgical microscope. As in other surgical
fields, there is a trend towards minimally invasive intervention in the field of otology by the use of endoscopes. It was felt that
budding otologists should adapt to the newer technology and acquaint themselves with both methods of ear surgery.
With this goal, this study was conducted to compare the results of microscopic and endoscopic assisted type I tympanoplasty
surgery in cases of chronic otitis media mucosal disease as performed by a senior resident.

\section{MATERIALS AND METHODS}

This was a prospective, randomised, controlled study conducted by the Dept. of ENT, HNS at a tertiary care centre in Kolkata, India, from January 2016 to December 2017. 50 patients undergoing type I tympanoplasty were classified into two groups; endoscopic tympanoplasty (ET, $n=25$ ) and microscopic tympanoplasty (MT, n= 25). The sample size required was taken for convenience.

\section{RESULTS}

Need for canaloplasty was felt in 8 cases under the MT group, while none was required in the ET group.

\section{CONCLUSION}

Endoscopic tympanoplasty is a safe alternative to microscopic method with comparable results in hearing and graft uptake. Its use and practice must be encouraged for all prospective otologists.

\section{KEY WORDS}

Endoscopy; Tympanoplasty; Canaloplasty.

HOW TO CITE THIS ARTICLE: Murari M, Ajay M. Comparison between microscopic and endoscopic assisted tympanoplasty- a beginner-otologist's perspective. J. Evolution Med. Dent. Sci. 2018;7(43):4625-4628, DOI: 10.14260/jemds/2018/1032

\section{BACKGROUND \\ The ear is one of the few organs of the body with very} complex and intricate anatomy, visualising and operating on the ear requires a very good orientation and excellent optics. The operating microscope has continued to be the workhorse of ear surgeries for several decades. The recent introduction in the 1990s of the endoscope through the ear has enabled the exploration of hidden areas and the rediscovery of a complex anatomy consisting of ligaments, folds and bone not otherwise easily visible by microscopic techniques. ${ }^{(1,2)}$ It has become a new tool in the armamentarium for otology surgery. The endoscope approach is increasingly being used for almost all types of otologic surgeries from ventilation tube insertion to cochlear implantation. ${ }^{(3,4)}$ Hence, the need for all budding otology surgeons to acquaint themselves to surgical practices using the endoscope.

Chronic Otitis Media (COM) is a worldwide health problem causing loss of productivity in professional as well as social life. Tympanoplasty, the repair of the tympanic membrane with assessment of the middle ear, hence is one of

'Financial or Other Competing Interest': None.

Submission 02-05-2018, Peer Review 07-10-2018,

Acceptance 13-10-2018, Published 22-10-2018.

Corresponding Author:

Mallick Ajay,

Department of ENT

Base Hospital,

Delhi Cantt,

New Delhi-110010, India

E-mail: mallick_doc@yahoo.com

DOI: $10.14260 /$ jemds/2018/1032 the most common surgeries in otology. To amalgamate the newer technology with the learning experiences from the past, we undertook the study to compare the results of type I tympanoplasty performed by microscope and by endoscope assisted as performed by a fledgling otologist. The learning objectives were-

1. To study the merits and demerits of endoscope assisted tympanoplasty.

2. To study the merits and demerits of microscope assisted tympanoplasty.

\section{MATERIALS AND METHODS}

This was a prospective, randomised, controlled study conducted by the Dept. of ENT, HNS at a tertiary care centre in Kolkata, India from January 2016 to December 2017. 50 patients undergoing type I tympanoplasty were classified into two groups: Endoscopic tympanoplasty $(E T, n=25)$ and Microscopic tympanoplasty (MT, $\mathrm{n}=25)$. The sample size required was taken for convenience.

\section{Study Area}

Department of ENT at a tertiary care centre in Kolkata, India.

\section{Study Population}

All patients attending ENT OPD who had satisfied all the inclusion criteria mentioned below during the study period.

\section{Study Period}

The study was conducted between January 2016 and December 2017. 
Ethical clearance was obtained from the Institutional Ethics Committee and the study was approved by the Scientific Review Committee of the Institute. Informed written consent was taken from all the participants.

\section{Sample Size}

50 patients.

\section{Study Design}

A prospective, randomised, controlled study.

\section{Parameters Studied}

1. Percentage of graft uptake.

2. Duration of surgery.

\section{Inclusion Criteria}

1. Subjects with inactive and quiescent COM- Mucosal disease.

2. Age between 12 - 70 years of both genders.

3. Willing for study with written informed consent.

4. Subjects with tympanic membrane perforation due to COM or trauma.

5. Subjects with inactive and quiescent COM- Mucosal disease.

\section{Exclusion Criteria}

1. Patients with mastoiditis or other complications.

2. Patients for revision surgery.

3. Patients with ossicular fixation/ discontinuity.

4. Patient with sensorineural hearing loss.

5. Patients with squamous active disease.

6. Associated diseases of external ear such as Otomycosis, Otitis externa.

7. Any systemic disease such as Diabetes mellitus, Malignancy.

\section{Group Allocation}

Allocation of patients to the two groups was done with the use of computer generated random allocation numbers. The allotment process was totally independent based on serial numbers allotted by the office staff with the surgical team not being involved at any stage and blinded to the whole process, as to which patient goes for which procedure. The results were assessed by a different team of physicians on follow-up with results and observations entered on individual serial numbers allotted rather than procedure which were later matched with the specific intervention undertaken based on the serial number allotted. The compilation with analysis of data was done on conclusion of study.

\section{Anaesthesia}

All cases were done under local anaesthesia using 2\% Lignocaine with 1: 200000 Adrenaline for injection and 4\% Lignocaine for topical use.

\section{Surgery/ Microscopic Method}

- All surgeries performed using Moller-Wedel operating microscope.

- Approach- Postaural Wilde's incision.

- Posterior meatotomy done.

- Margins of perforation freshened and tympanomeatal flap raised.
- Incision at $5 \mathrm{~mm}$ from tympanic annulus, 12 - 6 0'clock position with a circular knife.

- Elevation of the tympanomeatal flap- in all the cases superiorly based flap.

- Ossicular and middle ear status assessed.

- Graft placement- temporalis fascia placed by underlay technique and TM flap repositioned.

\section{Endoscopic Method (Fig. 1)}

- $0^{0}$ and 300, $17 \mathrm{~cm}$ long, $2.7 \mathrm{~mm}$ wide Karl-Storz rigid endoscope.

- Approach- Per meatal, purely endoscopic (under monitor visualisation).

- $2 \mathrm{~cm}$ hairline incision to harvest the temporalis fascia graft.

- Freshening of the margins of perforation.

- Incision taken $5 \mathrm{~mm}$ from tympanic annulus, 12 - 6 O'clock position with circular knife.

- Elevation of the tympanomeatal flap- in all the cases superiorly based flap was taken.

- Ossicular and middle ear status assessed.

- Graft placement- temporalis fascia placed by underlay technique and TM flap repositioned.

\section{Follow-Up}

Cases in both the groups were followed up for minimum 06 months. Uptake of the tympanic membrane and hearing was assessed at 03 and 06 months post-surgery. An intact mobile tympanic membrane with closure of air-bone gap less than or equal to $15 \mathrm{~dB}$ at six months post-operation was considered.

\section{Statistical Analysis}

Data was analysed using SPSS software with 20 version. The statistical analysis was done by using Chi-square test. Student's test and Fisher's test was used.

\section{RESULTS}

50 cases were examined, dividing into two groups and each group containing 25 cases were selected for the study. Parameters studied were age and sex distribution amongst the demographic profile and the following surgical parameters-

a. Duration of surgery.

b. Gain in hearing as assessed by PTA.

c. Success of graft uptake.

The age of the patients ranged from 12 to 70 years. Maximum preponderance $(50 \%)$ of cases were in their second and third decades of life. The mean age was 36.96 yrs. The male patients $(28 / 50)$ predominated over females $(22 / 50)$ in this series in the M: F ratio of 1.2 : 1 . The demographic data, preoperative, operative and postoperative surgical results of each group are summarised in Table I. Details of observations and results of the two groups studied are mentioned below and summarised in Table II.

\section{Duration of Surgery}

Endoscope assisted tympanoplasty required an average 76.96 mins (63 - 96 mins range) and microscopic tympanoplasty required an average of 115.92 mins (92 - 141 mins range). 


\section{Need for Canaloplasty}

Out of the total 50 cases, 8 cases (32\%) in Microscopic group required canaloplasty for adequate exposure and visualisation of TM. The commonest reason being an anterior canal wall bulge restricting the visualisation of the entire tympanic membrane and edges of the perforation. However, none in the endoscopic group required the same despite having canal bulge, as we could negotiate around the bulge and perform surgery with excellent visibility and delineation of anatomic details. This helped to save considerable time and head manoeuvre for better visualisation during surgery.

\section{Air-Bone Gap (A-B Gap)}

\section{Endoscope Assisted Tympanoplasty}

The endoscope assisted tympanoplasty group had an average preoperative conductive hearing loss of $27.84 \pm 8.01 \mathrm{~dB}$ (A-B gap). Post-operatively, there was decrease in average conductive hearing loss and an average of $12.36 \pm 2.69$ at 3 months and $11 \pm 2.42 \mathrm{~A}-\mathrm{B}$ gap at 06 months respectively.

\section{Microscope Assisted Tympanoplasty}

The microscopic tympanoplasty group had an average preoperative conductive hearing loss of $26.92 \pm 6.22 \mathrm{~dB}$ airbone gap (A-B gap). When comparing the preoperative results with post-operative results, both at 3 months and 6 months using t-test for dependent means.

\section{Status of Neotympanum/ Graft Uptake}

At 03 months, 02 cases in microscopic and 01 case in endoscopic group had residual perforation with a success rate of $(92 \%)$ and $(96 \%)$ respectively. The overall success rate was $(96 \%)$ with no marked complications.

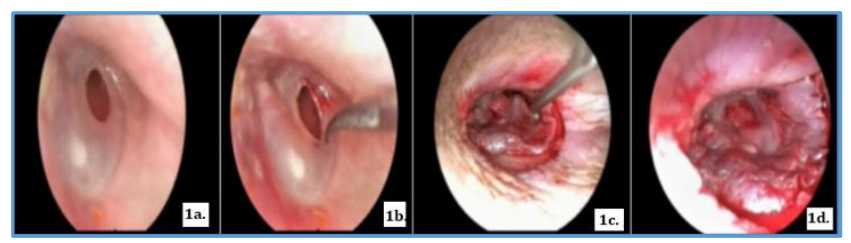

Figure 1. (Endoscopic View- 00). 1a. Central Perforation, 1b. Freshening the Margins of Perforation, 1c. Tympanomeatal Flap Raised, 1d. Perforation covered with Graft TM Flap being Repositioned

\begin{tabular}{|c|c|c|c|}
\hline Variable & $\begin{array}{c}\text { Endoscopic } \\
\text { Group N= 25 }\end{array}$ & $\begin{array}{c}\text { Microscopic } \\
\text { Group N= 25 }\end{array}$ & P value \\
\hline $\begin{array}{c}\text { Age (Years) } \\
\text { Mean }( \pm \text { SD) } \\
\text { Range }\end{array}$ & $\begin{array}{c}37.44( \pm 14.43) \\
13-67\end{array}$ & $\begin{array}{c}36.48( \pm 13.21) \\
20-68\end{array}$ & $0.807^{*}$ \\
\hline $\begin{array}{c}\text { Gender } \\
\text { Male }\end{array}$ & 10 & 12 & \\
Female & 15 & 13 & $0.568^{* *}$ \\
\hline \multicolumn{2}{|c|}{ Table 1. Demographic and Descriptive Findings } \\
\hline
\end{tabular}

*T-test for two independent means, ${ }^{* *}$ Chi-square test.

\section{DISCUSSION}

The main objective of this study was of determining the advantages and disadvantages of endoscope when compared to the conventional operating microscope in tympanoplasty surgery. In our study, reduction in operation time in the endoscopic group (average $76.96 \pm 10.41$ ) as compared to the microscopic group (average $115.92 \pm 14.24$ ). Similar results were observed by Lakpathi $\mathrm{G}$ et al,(5) who studied 60 cases dividing into two groups of 30 each. In our study, 8 cases (32\%) in Microscopic group required canaloplasty for adequate exposure and visualisation of TM. The commonest reason to perform a canaloplasty being an anterior canal wall bulge restricting the visualisation of the antero-inferior quadrant. There was no need for doing canaloplasty in any of the cases of the endoscopic group. The endoscope was able to negotiate the various tortuosity of the ear canal and also helped visualise the hidden areas of the middle ear easily. This helped to save considerable time. Similar observations were made in other studies such as those conducted by Harugop et al(6) and Nayeon Choi et al.(7) Other studies also showed that need to frequently adjust the patient's head or to do canaloplasty was less, thereby saving operative time.(8-10)

A study conducted by Raj A and Mehar R showed that graft uptake is $90 \%$ in endoscopic method and $85 \%$ in microscopic method.(11) Similar results were observed by other studies.(7,12) One study reported after endoscopic tympanoplasty in paediatric $\operatorname{cases}^{(13)}$ and also in cholesteatoma surgery. ${ }^{(14)}$

With 01 residual perforation in both groups, the overall success rate was (96\%) with no marked complications. Similar inference was made by Yadav et al who concluded that endoscopic tympanoplasty is equally effective, less morbid and very cost effective in treatment of central perforations of the tympanic membrane.(8)

Binocular vision provided by the microscope was a boon, as it provided an excellent magnified surgical view. The twohand surgery helps to remove blood from the operation field and helps in tissue dissection. However, visualisation of deep and hidden spaces such as sinus tympani, epitympanum and facial recess are limited, needing further soft tissue dissection or bone drilling. Similar reports are available in literature. $(3,4,15,16)$

We found the following advantages of endoscope: Excellent magnified image with a good resolution, minimal effort to visualise the nook and corners of middle ear cavity, magnification achieved by getting endoscope closer to surgical field, antero-inferior recess region of ear canal could be visualised easily and difficult areas of middle ear cavity to visualise under microscope like sinus tympani could be observed and evaluated using an endoscope.

The single hand performance of the surgical procedure is the most disadvantage of the endoscope in otology surgery. One hand is engaged in holding the scope, virtually limiting the surgery to be performed with one hand. Excessive bleeding makes the surgery more taxing and time consuming during endoscopic surgery, while it is easily manageable in microscope-assisted ear surgery. Similar experiences were reported in studies by Tarabichi(10) and Karhuketo et al.(12) Meticulous haemostasis is therefore essential in endoscopic ear surgery. Use of a stand to fix the endoscope helps to make both hands free to perform the surgery without engaging one hand to hold the endoscope.(5) Arm strain from prolonged holding of the endoscope is also reduced. There is an apparent loss of depth perception using the endoscope with the camera, as it provides a monocular vision as compared to the binocular vision provided by microscope.(11) This is more apparent to the beginner who has learnt ear surgery with the microscope. Adjustment to the endoscope needs a learning 
curve; however, adaption to the endoscope is fast and one learns from experience.

\section{CONCLUSION}

Our study shows that endoscopic tympanoplasty is a safe alternative to microscopic method. The results and complications were comparable for both methods. Endoscope gives excellent around the corner visibility, lesser need of canaloplasty, lesser operating time, minimal external incision and scarring. There is also the bonus of cheaper and portable operative setup. Major limitations are single-handed operation technique, recurrent soiling of scope and a learning curve.

\section{ACKNOWLEDGEMENTS}

The authors acknowledge the guidance of Dr. Ramakrishna N, Dr. Bhalla V and Dr. Roy Ravi from the Dept. of ENT, Command Hospital, Kolkata in the research work.

\section{REFERENCES}

[1] Thomassin JM, Duchon-Doris JM, Emram B, et al. Endoscopic ear surgery: initial evaluation. Ann Otolaryngol Chir Cervicofac 1990;107(8):564-70.

[2] Marchioni D, Alicandri-Ciufelli M, Piccinini A, et al. Inferior retrotympanum revisited: an endoscopic anatomic study. Laryngoscope 2010;120(9):1880-6.

[3] Ayache S, Tramier B, Strunski V. Otoendoscopy in cholesteatoma surgery of the middle ear: what benefits can be expected? Otol Neurotol 2008;29(8):1085-90.

[4] Tarabichi M. Endoscopic management of cholesteatoma: long-term results. Otolaryngol Head Neck Surg 2000;122(6):874-81.

[5] Lakpathi G, Sudarshan Reddy L, Anand. Comparative study of endoscope assisted myringoplasty and microscopic myringoplasty. Indian J Otolaryngol Head Neck Surg 2016;68(2):185-90.
[6] Harugop AS, Mudhol RS, Godhi RA. A comparative study of endoscope assisted myringoplasty and micrsoscope assisted myringoplasty. Indian J Otolaryngol Head Neck Surg 2008;60(4):298-302.

[7] Choi N, Noh Y, Park W, et al. Comparison of endoscopic tympanoplasty to microscopic tympanoplasty. Clin Exp Otorhinolaryngol 2017;10(1):44-9.

[8] Yadav SP, Aggarwal N, Julaha M, et al. Endoscope assisted myringoplasty. Singapore Med J 2009;50(5):510-2.

[9] Rosenberg SI. Endoscopic otologic surgery. Otolaryngol Clin North Am 1996;29(2):291-300.

[10] Tarabichi M. Transcanal endoscopic management of cholesteatoma. Otol Neurotol 2010;31(4):580-8.

[11] Raj A, Meher R. Endoscopic transcanal myringoplasty. -a study. Indian J Otolaryngol Head Neck Surg 2001;53(1):47-9.

[12] Karhuketo TS, Ilomaki JH, Puhakka HJ. Tympanoscope assisted myringoplasty. ORL J Otorhinolaryngol Relat Spec 2001;63(6):353-8.

[13] Dundar R, Kulduk E, Soy FK, et al. Endoscopic versus microscopic approach to type 1 tympanoplasty in children. Int J Pediatr Otorhinolaryngol 2014;78(7):1084-9.

[14] Hanna BM, Kivekas I, Wu YH, et al. Minimally invasive functional approach for cholesteatoma surgery. Laryngoscope 2014;124(10):2386-92.

[15] Presutti L, Marchioni D, Mattioli F, et al. Endoscopic management of acquired cholesteatoma: our experience. J Otolaryngol Head Neck Surg 2008;37(4):481-7.

[16] Marchioni D, Villari D, Alicandri-Ciufelli M, et al. Endoscopic open technique in patients with middle ear cholesteatoma. Eur Arch Otorhinolaryngol 2011;268(11):1557-63. 